\title{
PROCESOS DE DEMOCRATIZACIÓN. DERECHOS POLÍTICOS Y MICROESFERAS DE LO PÚBLICO: TENSIONES Y ARTICULACIONES POLÍTICAS PARA UN HORIZONTE PLURINACIONAL
}

\author{
ANA VICTORIA BRITOS CASTRO ${ }^{1}$
}

\section{RESUMEN}

En la pregunta por un horizonte plurinacional en Bolivia hoy, es central repensar los modos en que se han llevado a cabo ciertos procesos de lucha, en este caso lo que se consolidó como la Guerra del Agua y la Coordinadora en Defensa del Agua y de la Vida y, los sujetos políticos que se configuran a través de dichas prácticas sociales, políticas y culturales. En este sentido, hacer filosofía política latinoamericana y específicamente boliviana implica prestar atención a procesos democráticos y descolonizadores donde la lucha social y política funciona como un modo de relacionarse con la realidad y con un pensamiento colectivo, es decir, nutrir la pregunta por las condiciones de posibilidad de las diferentes sujetividades políticas (Roig, 1981) (Roig, 2002).

Palabras clave: Procesos de democratización, microesferas de lo público, prácticas descolonizadoras, sujetos políticos, horizonte plurinacional.

\footnotetext{
${ }^{1}$ Candidata a Doctora en Filosofía del Centro de Investigaciones de la Facultad de Filosofía y Humanidades (CIFFyH), Universidad Nacional de Córdoba. Consejo Nacional de Ciencia y Tecnología (CONICET). Afiliada a la Universidad Nacional de Córdoba (Argentina) y al Consejo Nacional de Ciencia y Tecnología -CONICET- (Argentina). Betania 2954, Barrio Escobar. Código postal 5009, Córdoba, Argentina. Correo electrónico: anivritos@hotmail.com
} 


\section{DEMOCRATIZATION PROCESSES. POLITICAL RIGHTS AND THE PUBLIC BEADS: POLITICAL TENSIONS AND ARTICULATIONS FORPLURINATIONAL HORIZON}

\section{ABSTRACT}

About the question for a plurinational horizon in Bolivia today is central rethink the ways they have conducted certain processes of struggle, in this case what was established as the Guerra del Agua and the Coordinadora enDefensa del Agua y de la Vida and political subjects that are configured through these political and cultural social practices. In this sense, make Latin American political philosophy and specifically Bolivian involves paying attention to democratic and descolonizing processes, where social and political struggle functions as a way of relating to reality and a collective thought, ie, inspire the question of the conditions possibility of different political subjectivities.

Keywords: Democratization processes, public beads, descolonizong practices, political subjects, plurinationalhorizont.

\section{Introducción}

Materialidad de la crisis que se asemeja a una rebelión que en sí mismo no tiene cómo devenir revolución, pero al mismo tiempo bloquea, de manera continua, la restauración de un orden fundado en la mera estabilidad. (Colectivo Situaciones, 2009)

Este trabajo pretende trazar un camino posible para re-pensar los modos en que se han llevado a cabo ciertos procesos de lucha, en este caso lo que se articuló como la Guerra del Agua y la Coordinadora en Defensa del Agua y de la Vida y, las sujetividades ${ }^{2}$ políticas que se configuran a través de dichas prácticas

\footnotetext{
${ }^{2}$ Resulta relevante remarcar que la propuesta epistemológica desde donde se articula este trabajo tiene como centro la perspectiva del filósofo argentino Arturo Roig, donde el término para nombrar a los diversos sujetos políticos es sujetividades políticas. La diferencia entre subjetividades y sujetividades radica en el desplazamiento epistémico de un único sujeto capaz de construir conocimiento, un sujeto esencialista, universalista, acuñado en el racionalismo moderno hacia un discurso de lo social que, en tanto objeto filosófico implica la manera de indagar los modos en que "...los sujetos se ponen a sí mismos como valiosos..." (Roig, 1981, p.11). El eje de las investigaciones propias de la historia de las ideas latinoamericanas consiste y me permite mostrar que la afirmación del sujeto implica la construcción de una filosofía para sí, para su propia realidad
} 
sociales, políticas y culturales ${ }^{3}$. Es en este sentido, que hacer filosofía política latinoamericana y, específicamente, boliviana implica prestar atención a procesos democráticos y descolonizadores en los que la lucha social y política funciona como un modo de relacionarse con la realidad y con un pensamiento colectivo, es decir, nutrir la pregunta por las condiciones de posibilidad de las diferentes sujetividades políticas (Roig, 2011).

Desde una línea crítica a la modernidad política occidental y a la operación de colonización y subjetivación que le es propia, este escrito no apunta a una reconstrucción del pasado y del presente ideológico. Por el contrario, se trata de participar en la reconstrucción de una de las tantas manifestaciones culturales teniendo presente los escenarios de lucha y resistencia. Consideramos valioso pensar nuevamente una filosofía política latinoamericana que ponga en tensión las situaciones de dependencia que aún hoy se reproducen sobre la base de relaciones de dominación y subalternidad. Intentaremos mostrar cómo la experiencia de la Guerra del Agua y los ciclos de rebeliones que comenzaron a partir del 2000 en Bolivia, son un claro ejemplo de ello.

histórica y social. Roig sostiene "... ese sujeto que se afirma o se niega a sí mismo, es inevitablemente un sujeto de discurso" (Roig, 1981, p. 16). Es esta construcción teórica y metodológica la que refiere a las sujetividades políticas -o sujetos colectivos- como morales emergentes, como apertura en el debate de lo político en su dimensión crítica. (Roig; 2002).

${ }^{3}$ Este artículo surge a partir de una Ponencia que fue presentada en el XIV Simposio de Filosofía Política, Lo público y lo privado en el espacio de lo político. Organizado por la Asociación Iberoamericana de Filosofía Política, conjuntamente con la Universidad de Valparaíso, Universidad Diego Portales, Universidad Adolfo Ibáñez y la Universidad de Chile. Valparaíso-Chile. En la Mesa titulada: Filosofía política desde América Latina: variaciones y re-apropiaciones de lo público y lo privado, en noviembre del 2015. En dicha oportunidad se dieron fructíferos diálogos durante tres días que fueron de gran aporte para la ampliación de las ideas presentadas y que se articularon en la elaboración de este trabajo, véase (Britos Castro, 2015a). 


\section{La Guerra del Agua y la Coordinadora en defensa del Agua y de la Vida. Dos procesos de democratización y lucha para pensar la cuestión del sujeto político.}

"...la vigorosa capacidad social de intervenir en asuntos públicos de múltiples y polifónicas maneras abrió un espacio tiempo de Pachakuti; esto es, configuró una situación social de trastocamiento de lo que hasta entonces había sido admitido como normal y cotidiano: la prerrogativa de unos hombres y mujeres, de cierta condición social y adscripción étnica, a mandar y decidir sobre el destino y suerte de todos los demás..."

Raquel Gutiérrez Aguilar (2008)

En primer lugar, es central desmontar el proceso moderno, occidental y su intrínseca relación, desde el comienzo, con el proceso político-colonial. Lo atrapante del vínculo modernidad política-colonial en la clave de la construcción de un pensamiento "otro" está en reconfigurar al proceso moderno en sus pasados y presentes regionales y locales. Para ello, es necesario romper con los esencialismos, los estatismos y los universalismos que hicieron y hacen de los discursos y de las prácticas de los sujetos del Sur meros reproductores, y los alejan de la historización y contextualización en sus diferencias.

Es de esta manera que, la modernidad política-colonial ha configurado el discurso en el cuál las sociedades modernas, se expresan como un conjunto desordenado de fragmentos confrontados y antagónicos subordinados por el capital, unificados ilusoriamente en totalidades aparentes (Tapia, 2008). Totalidades que se constituyen a sí mismas como Estados-nación mediante la articulación de dispositivos políticos posibilitadores de estructuras de tiempo y espacio que funcionan conteniendo los conflictos internos. La pregunta central aquí sería cuáles son las sujetividades intersticiales que operan como exceso y desborde de la propia modernidad/colonial y cuáles sus condiciones de posibilidad.

Entonces, en segundo lugar, resulta relevante revisitar el concepto moderno de sujeto político. La cuestión del sujeto, la pregunta por "eso que somos" y su emancipación se articuló en el seno de dos discursos totalizantes (Etiene Balibar, 
2013). Por un lado, el discurso político de lo universal, tanto de valores como de derechos y por el otro, un discurso de la diferencia antropológica ${ }^{4}$.

\section{En palabras de Balibar (2013)}

(...) el "sitio" de la cuestión del sujeto y de su emancipación en la época moderna (o mejor, en el campo de lo que nos es necesario llamar problemáticamente la "modernidad", a la cual pertenecemos siempre, por una parte por lo menos: al menos es nuestra cuestión, la cuestión de "eso que somos" y sobre todo eso que devenimos), vino a coincidir tendencialmente con la unión de un discurso político de lo universal (no solamente de "valores" universales, sino de derechos universales) y un discurso de la diferencia antropológica (este mismo debilitado de acuerdo con una multiplicidad de esquemas de identificación y normalización, de lo cual la reflexión foucaultiana sobre lo "anormal" nos habrá dado un ejemplo típico, pero no directamente generalizable) (...) Como se vió a los sujetos de la colonia, las mujeres, las minorías sexuales, o los criminales y lo locos, el apelar su exclusión interior lo hacen a la vez en nombre del "derecho a la diferencia" y en nombre de la "humanidad común" (pp. 31,36).

Desde la crítica de Balibar repensar al sujeto no como una "esencia humana genérica" o el destinatario de una "interpelación trascendental", sino como un sujeto históricamente situado, que habla de sí mismo, que puede configurarse como el "objeto de una diferencia continúa", en un sentido jamás "revelado" o jamás "determinado" de manera unívoca posibilita un intersticio en la modernidad política-colonial (Balibar, 2013). Este sujeto que no es único, fijo y universal, fluye heterogéneo y polifónico y se valora a sí mismo, a sus luchas, a sus rebeliones y

\footnotetext{
${ }^{4}$ Etiene Balibar afirma: "La primera es aquella de la posibilidad de la antropología filosófica, o mejor dicho del sentido de la pregunta antropológica en filosofía. Esta cuestión no puede ser independiente de la historia, ni como historia "extendida" de las metamorfosis de lo universal y sus lenguajes, ni como historia "reciente" de los debates de las escuelas en torno de la pregunta "¿Qué es el hombre?" (Balibar, 2013,pp. 36-37) , sostiene "...el "sitio" de la cuestión del sujeto y de su emancipación en la época moderna (o mejor, en el campo de lo que nos es necesario llamar problemáticamente la "modernidad", a la cual pertenecemos siempre, por una parte por lo menos: al menos es nuestra cuestión, la cuestión de "eso que somos" y sobre todo eso que devenimos), vino a coincidir tendencialmente con la unión de un discurso político de lo universal (no solamente de "valores" universales, sino de derechos universales) y un discurso de la diferencia antropológica (este mismo debilitado de acuerdo con una multiplicidad de esquemas de identificación y normalización, de lo cual la reflexión foucaultiana sobre lo "anormal" nos habrá dado un ejemplo típico, pero no directamente generalizable)", "Como se vió a los sujetos de la colonia, las mujeres, las minorías sexuales, o los criminales y lo locos, el apelar su exclusión interior lo hacen a la vez en nombre del "derecho a la diferencia" y en nombre de la "humanidad común" (Balibar, 2013, pp. $31,36)$.
} 
memorias colectivas. Según Roig (2011), aun cuando para llevar a cabo esa tarea de reivindicación social y política "deba entregarse a enunciar principios tan universales que pareciera que ha vuelto a olvidarse de sí" (p.181).

Sin embargo, una clave para pensar los sujetos políticos portadores de rebeliones e insurgencias como fueron la Guerra del Agua y la formación de la Coordinadora, son las reivindicaciones por la igualdad y el acceso a la ciudadanía que pasa por la refutación de las diferencias, ya sea tanto en su definición misma como en cuanto a la función institucional a la cual es asignada (Balibar, 2013). Siguiendo a este autor, bajo la operación moderna derecho a la diferencia o en nombre de la humanidad común se han borrado los diversos sujetos políticos portadores de derechos: los sujetos coloniales, raciales, étnicos, las mujeres, las minorías sexuales, los locos.

En esta línea crítica retomamos la idea planteada en la introducción: pensar nuevamente desde la filosofía política latinoamericana precisa poner en tensión las situaciones de dependencia que aún hoy se reproducen sobre la base de relaciones de dominación y subalternidad. No se concibe a los procesos históricos-políticos a partir de sujetos universales, abstractos y constituidos por una finalidad pre-fundamentada. Se indaga, por el contrario, en qué medida la democracia presenta múltiples desbordes del espacio de lo público que exceden a los dos modos reduccionistas que se articulan en la modernidad para contener a los sujetos políticos: el sistema de partidos o la administración política.

\subsection{La Guerra del Agua}

Así se dio a llamar a la serie de levantamientos populares, a las experiencias de insurrección y resistencia que conformaron un ciclo de rebeliones de cochabambinos y cochabambinas en contra de las políticas de privatización del agua a partir de septiembre de 1999, hasta abril de 2000. Estas movilizaciones marcaron un quiebre en la historia boliviana de las últimas décadas. No estuvieron pensadas en términos de una revolución o un cambio macro del poder político y el orden social, siguiendo a Luis Tapia (2007b), por el contrario tenían fines 
puntuales que, a raíz del movimiento masivo de demandas comunes tensionaron cuestiones macropolíticas y económicas. Fue un momento de irrupción en la realidad social, con un potencial de lucha creativo y emancipatorio, que "tuvo la capacidad de desordenar el sentido común de las cosas, el orden vigente de lo real, y abrir la posibilidad de una profunda transformación de la realidad existente en el país"(Linsalata, 2015, p.156).

Lucía Linsalata (2015) remarca dos elementos centrales que hicieron eco en la insubordinación popular y en el cuestionamiento del orden instituido. Por un lado, el deseo de los hombres y las mujeres movilizadas de poner un límite a las privatizaciones de los bienes comunes y reapropiarse de la capacidad colectiva de autogestión para decidir sobre el futuro de sus territorios y de sus vidas. Por otro lado, el posicionamiento de una otra forma de entender y hacer política, el asambleísmo, cuyos principales criterios fueron la deliberación abierta y polifónica y la horizontalidad en la toma de decisiones, con el fin de articular la pluralidad de fuerzas movilizadas (Linsalata, 2015). Ambos elementos reconfiguraron el orden simbólico existente en la sociedad boliviana en esos años y comenzaron a desear aquellos momentos de insurgencia, marcando el sentido de las consignas colectivas y del horizonte de transformación social.

El 3 de septiembre de 1999 fue el día en que el presidente Hugo Banzer y sus funcionarios firman, a puertas cerradas, un contrato de concesión del servicio de agua potable y alcantarillado de la ciudad de Cochabamba con la empresa Aguas del Tunari, un consorcio privado compuesto por la empresa transnacional Bechtel ${ }^{5}$ y ciertos capitales locales. Linsalata (2015) relata cómo esta concesión fue hecha pública solo dos meses después de la suscripción del acuerdo, el 20 de octubre de 1999 cuando el Parlamento boliviano aprobó la nueva Ley de Agua Potable y Servicios Básicos (Ley 2029), mediante la cual se legalizó el contrato con Aguas del Tunari. El 1 de noviembre Aguas del Tunari tomó posesión de las instalaciones de la empresa pública SEMAPA. Mediante la aprobación de la Ley

\footnotetext{
${ }^{5}$ La empresa Bechtel Group Inc., mega corporación estadounidense. Para mayor ampliación véase (Linsalata, 2015, p.159).
} 
2029 el Parlamento boliviano autorizó también, a través de la Superintendencia del Agua $^{6}$, el despojo por parte del capital privado de los sistemas locales de gestión de agua, sistemas públicos y comunitarios existentes en el país, logrando el monopolio absoluto del control del recurso natural. En palabras de la autora, "...la Superintendencia tenía la facultad de imponer la ley del mercado desde el anonimato del aparato burocrático y centralizador del estado, sin dejar a la gente ninguna posibilidad de apelación"(Linsalata, 2015, p.160).

El contrato con Bechtel concedía 40 años de monopolio sobre la gestión del servicio de agua potable en toda el área urbana, incluyendo las zonas periféricas donde se encontraban las gestiones comunitarias. Dada esta situación distintas organizaciones de Cochabamba decidieron movilizarse al percibir la promulgación de la Ley 2029 como un gesto de violación profunda a los derechos políticos y sociales. Esta violación a los derechos puso en riesgo el principio central que regula las complejas relaciones de reciprocidad, la densa textura de las prácticas en común (Linsalata, 2015, p.160).

El acceso al agua es una riqueza que la Pacha pone a disposición de todos y que por ello todos tienen la obligación de cuidar y gestionar colectivamente (Linsalata, 2015, p.160). La primera organización en levantarse fue FEDECOR (Federación Departamental Cochabambina de Regantes), integrada por campesinos quechua hablantes de los valles, quienes desde hace años venían luchando por el uso y las costumbres locales en el tema gestión de agua. ${ }^{7}$ Específicamente, fueron dos luchas las que posibilitaron que los distintos sistemas de aguas de los valles pudieran articular sus diferencias y tomar en sus manos la

\footnotetext{
${ }^{6}$ La Superintendencia del Agua en ese contexto actúo como una nueva institución de carácter nacional nombrada por el Congreso y totalmente desvinculada con las realidades regionales. Para mayor ampliación véase (Linsalata, 2015, p.160).

${ }^{7}$ En las zonas rurales de los valles de Cochabamba existen centenas de sistemas comunitarios de riego que se encargan de gestionar autónomamente el acceso, manejo y cuidado del agua. Entre estos sistemas algunos tienen orígenes muy antiguos desde la época incaica, otros comenzaron a operar después de la Reforma Agraria de 1953, otros como los sistemas de agua del área urbana se conformaron recientemente a partir del esfuerzo colectivo y del apoyo de ciertas ONGs.

En todos ellos, a pesar de las diferencias, el agua es autogestionada territorialmente por las familias usuarias con base en acuerdos comunales. El derecho colectivo sobre las fuentes de agua comunes es regulado a través de articulados sistemas de turnos y obligaciones recíprocas entre comunidades, llamados sistemas de "mitas y suyos". (Linsalata, 2015).
} 
lucha por lo común, que se consolidó como la Guerra del Agua. Por un lado, la pelea por la modificación de algunos artículos de la Ley de Participación Popular ${ }^{8}$ y por otro, la lucha en contra de las perforaciones de los pozos profundos por parte de SEMAPA, lucha que tuvo su momento álgido en la Guerra de los pozos en 1998.

\subsection{Cómo surge la Coordinadora en Defensa del Agua y de la Vida}

Los dirigentes de la FEDECOR decidieron, días antes de la aprobación de la Ley, organizar un seminario para informar lo que estaba sucediendo en el país y analizar colectivamente de qué manera la nueva normativa podía afectar las prácticas locales de los sistemas de riego. A este seminario asistieron dirigentes de varias organizaciones de base de los valles, sindicatos agrarios, juntas vecinales, lo que dio lugar a la manifestación en contra de la ley de agua y a convocatoria para el 4 de noviembre de 1999 al primer bloqueo carretero de 24 horas; bloqueo que fue violentamente reprimido por el ejército boliviano. Al mismo tiempo se organizaba un Comité en Defensa del Agua conformado por iniciativa de un grupo de profesionales cochabambinos que movilizaron a muchos ciudadanos.

Luego de la represión del 4 de noviembre, los ciudadanos decidieron reorganizarse en un encuentro llevado a cabo el 12 de noviembre en las sedes de la Federación de Fabriles de Cochabamba. A este encuentro asistieron los campesinos de FEDECOR, los integrantes del Comité en Defensa del Agua, los fabriles, los trabajadores precarios, varias organizaciones vecinales de base, activistas urbanos, logrando articular un espacio común de deliberación y confluencia. Desde este entramado de fuerzas sociales, políticas y culturales es que se organiza la Coordinadora en Defensa del Agua y de la Vida.

En estos momentos de conflicto social resulta interesante reflexionar en el modo a partir del cual las capacidades auto-organizativas de los entramados comunitarios se expresan en la superficie política bajo la forma de asambleas locales o barriales. Este tipo de sujeto político que opera desplazándose del

\footnotetext{
${ }^{8}$ Ley de Participación Popular véase (Tapia, 2007).
} 
subsuelo político (Tapia, 2008) hacia la superficie discursiva hegemónica y dominante provoca un tipo de composición o articulación de reconocimiento, explicación, reflexividad, valoración y proyección de estas realidades que se configura como episteme. Lo local opera como una condición de posibilidad de dichos sujetos, quienes son los protagonistas de estas luchas emancipatorias. (Britos Castro, 2015c).

En este sentido, la experiencia de la Guerra del Agua y la conformación de la Coordinadora precisan de ser pensadas como momentos constitutivos de un quiebre social. Esto porque se gestan como un momento de crisis y descomposición política que erosionaron y agrietaron las formas de dominación consolidadas en Bolivia hasta aquí. Los momentos constitutivos son el fundamento ideológico sobre el cual se asienta una sociedad (Zavaleta Mercado, 1986) y en este sentido se articula la historia y el análisis de dicha sociedad (Tapia,2002a). Son momentos de transformación significativa de la dirección de los procesos sociales, culturales, políticos y económicos de los sujetos políticos.

En palabras de Zavaleta Mercado (1986):

Son ciertos acontecimientos profundos, ciertos procesos indefectibles, incluso ciertas instancias de psicología común que fundan el modo de ser de una sociedad por un largo período. La interpelación en la hora de la disponibilidad general, que es la del momento constitutivo, está destinada a sobrevivir como una suerte de inconsciente o fondo de esta sociedad. (p. 45)

Y agrega:

El momento económico de la formación nacional y su momento ideológico o cultural son paralelos y se fundan ambos en el contexto dado por el momento constitutivo (...) a este momento causal no se le debe dar un contenido metafísico porque es lógico que cada sociedad vive varios momentos constitutivos de diferente intensidad. (Zavaleta Mercado, 1986, p. 51)

Desde el aporte de Zavaleta Mercado es que se puede afirmar que estas crisis y sus posteriores procesos políticos requirieron de un debate, de una reflexión, es decir, de la circulación del conocimiento político local, con el afán de colectar, trazar y proyectar elementos que pusieran en jaque al gobierno de turno. 
En otras palabras, una crisis política genera un tiempo que es de fluidez en el cual la imaginación y la experiencia son acción.

Bajó la consigna "el agua es vida, no mercancía"9 los cochabambinos y cochabambinas marcharon buscando poner en entredicho el principio central de la lógica mercantil-capitalista bajo la cual imponía su modelo el Estado boliviano. La Coordinadora convocó a asamblea ciudadana y al primer bloqueo llamado por esta, el 10 de enero del 2000 , el "bloqueo indefinido por la dignidad civil" (Linsalata, 2015). La lucha por el agua se extendió hasta febrero del 2000 donde día a día se incrementaba el conflicto entre el gobierno y la población movilizada. La segunda movilización del 14 de febrero se denominó "Toma de Cochabamba" y consistió en una acción masiva de ocupación pacífica de la ciudad, con la consigna:

NO, al contrato de concesión del agua cochabambina a la empresa pública SEMAPA; NO, a la Ley de Agua y Alcantarillado que ignoraba los derechos colectivos y a los usos y costumbres de la población; NO, a la elevación desmedida de las tarifas; Sí, a una revisión pública de la Ley de Agua en la que la población pudiera expresar sus necesidades. (Linsalata, 2015, p.181)

La lucha continúo y el 4 de abril los ciudadanos volvieron a paralizar la ciudad. Las manifestaciones también se extendieron hacia otros lugares del país en particular al altiplano norte, donde las comunidades aymaras bloquearon el Departamento de La Paz, "Ilegando en la cabecera municipal de Achacachi a quemar todas las instituciones públicas que representaban al estado (la alcaldía, la subprefectura, la policía, el puesto de tránsito y la cárcel)" (Linsalata, 2015, p. 183). La disputa duró hasta el 9 de abril con la toma por parte de la población de las instalaciones de la antigua SEMAPA y la expulsión definitiva de la trasnacional Bechtel. El 11 de abril el Estado boliviano derogó la Ley 2029 y promulgó la Ley de Modificación a la Ley de Agua, en la que se reconoció el derecho de los sistemas

\footnotetext{
${ }^{9}$ Consigna retomada del trabajo llevado a cabo por Linsalata recuperada en la Entrevista realizada a Fabián Condori, fundador y administrador de APPASS de Villa Pagador, el 13 de julio de 2010.
} 
autogestivos de seguir prestando servicios en sus comunidades ${ }^{10}$. El 12 de abril se levantaron los bloqueos.

Las luchas sociales y políticas dependen de cómo se organiza la estructura de conflicto en diversos momentos históricos, es decir, de cómo se jerarquizan las estructuras de dominación y se articulan los conflictos en términos de prioridad (Tapia, 2008). Es la estructura de conflicto la que sirve para nombrar la articulación del contexto de las crisis en las que se dan las rebeliones, la que contiene una línea de clivajes o divisiones sociales y políticas que organizan las relaciones de explotación y desigualdad y las relaciones de dominación y opresión (Tapia, 2008).

Esta serie de levantamientos en enero del 2000 en Cochabamba muestran como dentro de una práctica democrática hegemónica se generan espacios de acción que, en coyunturas críticas, se resignifican en espacios de resistencia y contestación al orden establecido (Britos Castro, 2014).

En esta línea es interesante problematizar cómo las lógicas modernas coloniales del Estado-nación se estructuran sobre la desorganización de las formas de políticas comunitarias (Gutiérrez Aguilar, 2015), (Linsalata, 2015), (Salazar Lohman, 2015). La totalidad política, económica y cultural que se construye en el discurso moderno del Estado obtura otros modos de acción y práctica social. Cuando a través de estos espacios de resistencia se actualiza la vida económica y política de un país, se fragmenta necesariamente la forma totalizadora en la que la sociedad se representa a sí misma, lo que conlleva a cambios de estructuras, de discursos y de sentidos en los distintos grupos sociales que la constituyen. Estas fisuras permiten visualizar los sujetos y lugares intersticiales que coexisten socavando el Estado-nación moderno y la factualidad del monopolio de la política (Tapia, 2008), (Tapia, 2015).

Desde aquí, pretendemos mostrar cómo se articula un tejido subterráneo de formas de lo político, formas de lo común que, sin dejar de visualizar las coordenadas estatales, buscan otros modos de relaciones sociales y económicas.

\footnotetext{
${ }^{10}$ Creación de “Entidades Prestadoras de Servicios de Agua Potables” (EPSA’s).
} 
Esto implica que el escenario de lo político se construye en la articulación de estructuras de autoridad o de autogobierno que emergen con las manifestaciones sociales y culturales. Este tejido subterráneo es el subsuelo político, espacios de democratizaciones que ocurren por debajo de la superficie política y que se reactualizan en la propia complejidad del movimiento de lo social. Este subsuelo político que no se reconoce, ni se asume, se produce como un exceso, como un excedente de la administración de la política estatal, que precisa ser re-pensado como la base de una estructura de conflicto, una estructura de rebelión.

De esta manera, la visibilidad política y social no sólo se da a través de las instituciones del capital y del Estado-nación, si no también mediante el entramado de la sociedad civil como lo fue la Coordinadora en el 2000 y los años siguientes ${ }^{11}$.

\section{Espacios y modos de lo público. Derechos políticos y microesferas de lo público. Articulando un horizonte plurinacional}

Como hemos mostrado en los párrafos anteriores hablar de la Guerra del Agua y de los procesos políticos y sociales que implicaron ese período histórico es hablar de otras formas políticas como son las comunitarias, las barriales, locales, asamblearias que coexisten con el Estado-nación, en numerosas ocasiones, en el ámbito de lo público.

Estos diversos tipos de organizaciones sociales son siempre un espacio y un modo de lo público que recuperando ciertas prácticas domésticas, prácticas de micro política, irrumpen en el espacio de lo macro social y sus voces se vuelven voces audibles para el discurso hegemónico y dominante. Estas rebeliones y luchas, expresan derechos políticos que operan construyendo procesos de democratización, tramando en estos sujetos políticos y en sus modos

\footnotetext{
${ }^{11}$ Desde este momento la Coordinadora se vuelve la principal estructura de rebelión, que tiende a emerger y a organizarse en los momentos de movilización general y crisis política (durante la primera parte de la década 2000). La Coordinadora se hizo necesaria para la articulación y la representación de una diversidad y pluralidad de organizaciones, fuerzas y opiniones. Responde, a la vez, a la condición de fragmentación inducida por la economía y política neoliberal, pero también a la diversificación y desarrollo de la sociedad civil.
} 
asamblearios de politizar la sociedad como claros ejemplos de la participación y pluralidad social.

En este marco, indagar respecto de los modos de la igualdad precisa revisitar las articulaciones y lazos que expresan los derechos políticos al ser estos una condición de posibilidad del conocimiento social, lo que permite entramar una pluralidad política.

Cuando existe un reconocimiento de los derechos es que se puede hablar de un espacio público. Uno de los principales derechos políticos es el derecho a la organización, otro es el de la libre expresión y otro el derecho a ser elegido autoridad y elegir autoridad (Tapia, 2007a). En este juego político es que podemos entender los movimientos sociales, las luchas y las articulaciones resultantes de estas, en el proceso democratizador del 2000 en Cochabamba. Desde aquí, resulta fértil comprender las acciones llevadas a cabo por los y las cochabambinas como prácticas de micro política que se traducen, se traman, se rearman en conjuntos de microesferas de lo público (Tapia, 2007a).

Con microesferas de lo público entendemos a los espacios donde se encuentran los mayores grados de participación, de compromiso y de responsabilidad política que tienen como horizonte la construcción colectiva de las relaciones de igualdad. Politizar de este modo las relaciones de igualdad tiene que ver con reconocer formas políticas de autogobierno, autogestionadas y la capacidad de los sujetos políticos de dirigir, co-gobernar y co-gobernarse produciendo un discurso social en relación a ellos mismos y a sus prácticas emancipatorias. Es a través de esta politización que se trabajan y se habitan las contradicciones inventadas por la propia modernidad colonial y capitalista y no, buscar integrarlas. (Silvia Rivera Cusicanqui, 2013). Es preciso para sostener una igualdad política en condiciones multiculturales y multisocietales ${ }^{12}$, en una

\footnotetext{
${ }^{12}$ El concepto de multisocietal se articula a partir del concepto de lo abigarrado que pensó Zavaleta Mercado para explicar la complejidad de Bolivia. Lo multisocietal contiene, dice Tapia, el primer rasgo de lo abigarrado: la coexistencia y sobreposición de diferentes formas sociales de diversa cualidad y tiempo histórico, pero no necesariamente la desarticulación y la operación de dominación colonial que de ella deriva en espacios de sobreposición. Para más detalle sobre esta discusión véase (Tapia, 2002b).
} 
sociedad abigarrada como la boliviana, reformar las formas de gobierno hegemónicas y por ello, es que diversas microesferas de lo público se re-articulan tanto en el espacio del gobierno nacional como en las formas políticas de lo local (Britos Castro, 2015b y 2015d).

Estas microesferas de lo público que se configuran a partir de prácticas descolonizadoras se traman de manera tal que penetran socavando lo público a niveles más generales como la política nacional. Esto conlleva a re-visitar el concepto de ciudadanía propio de la modernidad política. La ciudadanía, siguiendo a Tapia (2007a) es siempre una historia de constitución de sujetos políticos cuyo objetivo principal es modificar la sociedad ampliando los márgenes de la igualdad. Igualdad que se expresa para sí y para otro.

Re-pensar la ciudadanía, entonces, abre a la multiplicidad de formas de lo histórico-político, implica necesariamente revisar el ejercicio de la política misma. Las asambleas que dieron lugar a la Coordinadora son un conjunto de estructuras de autoridad que funcionaron paralelas al Estado-nación, que ponen en entredicho la cultura política liberal. Esto significa que los sujetos políticos tienen derecho a tener sus propias autoridades, autoridades sobre las cuales se puede ejercer algún vínculo de control, las cuales se posicionan como representantes frente al Estado (Tapia, 2007a). De esta manera, el modo en que se ejerce la ciudadanía y la mediación implica la representación política. Consiste en un proceso en el cual los sujetos como parte del ejercicio de sus derechos, primero construyen su organización, o se afilian a alguna, logran una política autónoma para intervenir en los espacios públicos. Tapia (2007) afirma que "pertenecen a una colectividad que articula un conjunto de bienes compartidos, a partir de intereses y condiciones sociales más o menos comunes, y es esa instancia organizativa colectiva la que luego ejerce la representación en relación al estado" (p. 52).

La ciudadanía en esta clave poniendo de relieve la igualdad política es el punto central para entender porqué las movilizaciones y levantamientos del 2000 pusieron en crisis no solo al gobierno boliviano, sino también a la sociedad civil. 
El reconocimiento de los derechos para intervenir en la superficie hegemónica de la política involucra necesariamente la reflexión en torno a los nuevos procesos de democratización social, cultural y económica. Estos procesos se inscriben en las crisis sociales que, exceden e implosionan desde la crítica a las desigualdades políticas, a la forma estatal. Para que exista igualdad política entre pueblos que tienen diferentes culturas y modos sociales es preciso que operen momentos de sincronicidad en las instituciones $y$ en las diversas organizaciones de la sociedad. Es central, como ya hemos mencionado, una reforma de las estructuras de gobierno que contenga y represente una composición de las formas políticas provenientes de las diversas culturas que se consoliden no solo como un espejo que refleja la multiculturalidad, la igualdad aparente (Tapia, 2002b), sino que potencie otros modos de hacer política desmontando necesariamente los monopolios económicos de la lógica del capital.

Un espacio filosófico-político que se entreteje en estas lógicas asamblearias y barriales es el de una política emancipatoria que se encuentra sobre la base de estos procesos de democratización y descolonización. Pensar los múltiples modos emancipatorios tiene que ver con, retomando la perspectiva de Gutiérrez Aguilar (2015), una política desde la autonomía. La autora los llama procesos de autoemancipación como un contenido particular y concreto desde la lógica autonómica. De cara a las luchas y rebeliones, en esta sintonía de la autoemancipación "se trata de pensar en y ocuparse de cuidar y expandir, de múltiples maneras, la capacidad autónoma para intervenir en los asuntos públicos" (Gutiérrez Aguilar, 2015, p. 61), de no ceder el lugar de la enunciación propio, construido con dificultad y en ese sentido dar la batalla por la igualdad política, que se mencionaba en el párrafo anterior.

En el canon argumental de la dominación y la explotación capitalista y neoliberal, advierte la autora, se inscribe la cara oculta del poder, "la sujeción de la capacidad de pensar y la imposición de que en la abstracción, todo sea igual al propio valor que se valoriza" (Gutiérrez Aguilar, 2015, p. 61). 
El sujeto político que se constituye y se articula en la Coordinadora, que erosiona y escapa, justamente a los conceptos occidentales, capitalistas y coloniales de la filosofía política moderna, ese subsuelo político, posibilita la multiplicidad de formas de vida que disputan y debaten sobre la lógica de la igualdad promoviendo prácticas auto-emancipatorias. La diversidad de prácticas políticas, sociales, culturales que se despliegan en un país multisocietal como Bolivia posibilita la perseverancia en una política emancipatoria que necesariamente ha articulado desde lo particular, lo local y la inestabilidad del orden existente, tensionando constantemente el despliegue de una vida más allá y contra la lógica del capital, mostrando modos autónomos de lo común. En palabras de Gutiérrez Aguilar (2015):

Mientras la sociedad esté desgarrada por brutales antagonismos, tal como lo está ahora -y lo estará durante bastante tiempo-, la política de la emancipación habrá de trastocar el orden que se le impone desde los múltiples particulares que genera y habita. La emancipación, en tal sentido, pues, es camino y trayecto, es esfuerzo por esclarecer los itinerarios y por ampliar y des-sujetarlos flujos de la energía social que, a fin de cuentas, son el fundamento de cualquier creación de novedad (p.62).

\section{Conclusión}

Para finalizar queremos resaltar que, aquello que se puede conocer de una sociedad depende de las configuraciones históricas, políticas, sociales y culturales que esa sociedad expresa y articula. Dichas configuraciones históricas permiten pensar prácticas y políticas descolonizadoras. En este sentido es que las movilizaciones y levantamientos que dieron lugar a la Guerra del Agua y la conformación de la Coordinadora en Cochabamba en el 2000 posibilitan pensar otros procesos de democratización. Se inscriben como el comienzo de un horizonte plurinacional, es decir, como la articulación de espacios de la vida política que son incompletos y que operan siempre como condición de posibilidad de nuevas formas y composiciones políticas. Ahora bien, pensar un Estado que tenga un horizonte plurinacional como objetivo y responsabilidad política requiere de continuar en profundidad este debate y esta discusión. 
Consideramos entonces que resulta heurísticamente fértil indagar por estos procesos políticos, ideológicos, económicos, sociales y culturales que ponen en jaque al Estado Plurinacional de Bolivia, en términos de formaciones políticas comunitarias, asamblearias y disruptivas de las formas políticas modernas y coloniales. En otras palabras, resulta relevante rehabitar la configuración de estas nuevas sujetividades políticas desde abajo que posibilitan un atravesamiento democrático de las crisis estatales en su conjunto. Sin embargo, como afirma el Colectivo Situaciones (2009), estos procesos democratizadores han sido traducidos de manera capitalista y neodesarrollista por parte del gobierno, que tradujo a las revueltas cochabambinas en argumentos para la recomposición del imaginario estatal-nacional.

En esa línea sigue siendo relevante preguntarse entonces por ¿cómo se construyen los Estados-nación en condiciones de yuxtaposición social, cultural, histórica, es decir en condiciones de abigarramiento?, ¿cómo se problematiza la cuestión de lo nacional y de lo nacional-popular heterogéneo y multisocietal?, en el seno de la construcción y articulación de las múltiples formas emancipatorias entramadas en los complejos procesos democráticos y descolonizadores en la Bolivia contemporánea.

\section{Referencias Bibliográficas}

Babeuf, G (2014). El manifiesto de los plebeyos y otros escritos. Buenos Aires: Godot.

Balibar, E (2013). Ciudadano sujeto: volumen 1: El sujeto ciudadano. Buenos Aires: Prometeo.

Britos Castro, A (2015). Desmontando el discurso colonial: sujetos y representaciones desde lo local. Una lectura a partir de Luis Tapia y Silvia Rivera Cusicanqui. Revista TELAR, Revista del Instituto Interdisciplinarios de Estudios Latinoamericanos, Facultad de Filosofía y Letras-Universidad Nacional de Tucumán, V. X (15), 118-133. Recuperado en http://filo.unt.edu.ar/wpcontent/uploads/2015/11/Telar-15-11-Lecturas-Britos.pdf.

Britos Castro, A (2015a, noviembre). Microesferas de lo público: tensiones y articulaciones políticas para un horizonte plurinacional. Ponencia presentada en el XIV Simposio de Filosofía Política, Lo público y lo privado en el espacio de lo político. Organizado por la Asociación Iberoamericana de Filosofía Política, 
conjuntamente con la Universidad de Valparaíso, Universidad Diego Portales, Universidad Adolfo Ibáñez y la Universidad de Chile. Valparaíso-Chile.

Britos Castro, A (2015b, septiembre).Heterogeneidad social y abigarramiento. Claves para pensar lo nacional-popular en la Bolivia contemporánea. Ponencia presentada en la Mesa: Revisitando el legado de Zavaleta Mercado para pensar Bolivia hoy: Estado, movimientos sociales y autonomía, en el I Simposio de Filosofía Latinoamericana Contemporánea y las VII Jornadas Intercátedras de Pensamiento Latinoamericano, UNC, Córdoba.

Britos Castro, A (2015c, agosto). Lecturas desde una filosofía política boliviana. Lo nacional-popular como problemática política actual. Ponencia presentada en el Panel: La Filosofía Latinoamericana Contemporánea en la Teoría Social en el I Congreso Latinoamericano de Teoría Social. ¿Por qué la Teoría Social? Las posibilidades críticas de los abordajes clásicos, contemporáneos y emergentes. Organizado por el Grupo de Estudios sobre Estructuralismo y Postestructuralismo. IIGG-Facultad de Ciencias Sociales-UBA.

Britos Castro, A. (2015d, marzo). Latinoamérica: diálogos a través de lo local. Desmontando el discurso colonial. Ponencia presentada en el II Congreso de Estudios Poscoloniales y III Jornadas de Feminismo poscolonial. Recuperada en http://www.idaes.edu.ar/sitio/noticias/novedades.asp?idNov=346\&tipo=idaes.

ISBN: 978-987-1435-89-0.

Britos Castro, A. (2014).Re-pensar lo subalterno. Indagaciones en torno a las definiciones de sujetos políticos latinoamericanos. La Paz: Autodeterminación.

Cerutti Guldberg, H(2007). Democracia e integración en Nuestra América (Ensayos). Mendoza: EDIUNC.

Cerutti Guldberg, H,(et. al.) (2008). Resistencia, democracia y actores sociales en América Latina. México: CIAL (UNAM)-Ed. Eón-Pensares y Queahaceres.

Chavéz, P, (et. al.) (2013). Procesos y proyectos democráticos en Bolivia. La Paz: Autodeterminación.

Colectivo Situaciones (2009). Inquietudes en el impasse. En Conversaciones en el impasse. Dilemas políticos del presente. Buenos Aires: Tinta Limón.

Cruz, G. (2009). La liberación indígena contemporánea en Bolivia. Crítica Filosófica a una Política-Estética Racializada. Córdoba: EDUCC.

Gago, V (2014). La razón neoliberal. Economías barrocas y pragmática popular. Buenos Aires: Tinta Limón.

García Linera, A (2008). La potencia plebeya. Acción colectiva e identidades indígenas obreras y populares en Bolivia. Buenos Aires: CLACSO-Prometeo.

Gutiérrez Aguilar, R. (2015). Horizonte comunitario-popular. Antagonismo y producción de lo común en América Latina, Cochabamba, Bolivia: SOCEEAutodeterminación. 
Gutiérrez Aguilar, R. (2008).Los ritmos del Pachakuti. Movilización y levantamiento popular-indígena en Bolivia (2000-2005). Buenos Aires: Tinta Limón.

Laclau, E (1996). Emancipación y diferencia. Buenos Aires: Ariel. Laclau, E \& Mouffe, C. (2010). Hegemonía y estrategia socialista. Hacia una radicalización de la democracia. México: FCE.

Linsalata, L (2015). Cuando manda la asamblea. Lo comunitario-popular en Bolivia: una mirada desde los sistemas comunitarios de agua de Cochabamba. Bolivia: SOCEE-Autodeterminación-Fundación Abril.

Mouffe, C (2009). En torno a lo político. Buenos Aires: FCE. Quijano, A (2006). Estado-nación y movimientos indígenas en la región Andina: cuestiones abiertas. Revista OSAL, Año VI. (19), 15-24. Buenos Aires: CLACSO. Recuperado en http://bibliotecavirtual.clacso.org.ar/clacso/osal/20110327050057/02Quijan.pdf.

Quijano, A (2000) Colonialidad del poder, eurocentrismo y América Latina. Lander Edgardo (comp.) La colonialidad del saber: eurocentrismo y ciencias sociales. Buenos Aires: CLACSO.

Quijano, A (2000). Colonialidad del poder y clasificación social.Journal of WordSystems Research. Vol XI. (2) Special Issue: Festchrift for Immanuel Wallerstein Part I. Departament of Sociology. Binghamton University State University of New York. Recuperado en http://jwsr.ucr.edu.

Rancière, J (1996). El desacuerdo. Política y filosofía. Buenos Aires: Ediciones Nueva Visión.

Rivera Cusicanqui, S (2014). Más allá del dolor y del folklor. En Os mil nomes da Gaia. Do Antropoceno à Idade da Terra. Coloquio Internacional, Casa de Rui Barbosa. Rio de Janeiro. Recuperada en www.osmilnomesdagaia.eco.br.

Rivera Cusicanqui, S (2010). Sociología de la Imagen. Una visión desde la historia colonial andina y Ch'ixinakaxutxiwa. Una reflexión sobre prácticas y discursos descolonizadores. En Ch'ixinakaxutxiwa. Una reflexión sobre prácticas y discursos descolonizadores. Buenos Aires: Tinta Limón.

Roig, A (2011). Rostro y filosofía de nuestra América. Buenos Aires: Una Ventana.Roig, A (2002). Ética del poder y moralidad de la protesta. Respuestas a la crisis moral de nuestro tiempo. EDIUNC. Mendoza.

Roig, A (1981). Teoría y crítica del pensamiento latinoamericano. México: FCE. Salazar Lohman, H (2015). Se han adueñado del proceso de lucha. Horizontes comunitario-populares en tensión y la reconstitución de la dominación en la Bolivia del MAS. Cochabamba: SOCEE-Autodeterminación.

Svampa, M (2016). Debates Latinoamericanos. Indianismo,desarrollo, dependencia y populismo. Buenos Aires: Edhasa.

Svampa, M (2014). Maldesarrollo. La Argentina del extrativismo y el despojo. Buenos Aires: Katz. 
Svampa, M (2008). Cambio de época. Movimientos sociales y poder político. Buenos Aires: Siglo XIX.

Tapia, L (2015a). La hegemonía imposible. La Paz: Autodeterminación. Tapia, L (2015b).El horizonte plurinacional. La Paz: Autodeterminación.Tapia, L (2012). Ciclos. La Paz: Autodeterminación.

Tapia,L (2009). La forma primordial e Intergubernamentalidad igualitaria. En Pensando la democracia geopolíticamente. La Paz: Comuna-CLACSO-Muela del Diablo.

Tapia, L (2008). Política salvaje. Bolivia: Muela del diablo.

Tapia, L (2007a).La igualdad es co-gobierno. La Paz: CIDES-UMSA, ASDISAREC y Plural editores.

Tapia, L (2007b). Bolivia: ciclos y estructuras de rebelión. En Svampa, M; Stefanoni, P [Comp.] Bolivia: memoria, insurgencia y movimientos sociales. Buenos Aires: CLACSO-OSAL-El colectivo.

Tapia, L (2002a).La producción del conocimiento local. Historia y política en la obra de René Zavaleta. La Paz: Muela del Diablo.Tapia, L (2002b). La condición multisocietal. Multiculturalidad, pluralismo, modernidad. La Paz: Muela del Diablo/CIDES-UMSA.

Tischler, S (2004). La forma clase y los movimientos sociales en América Latina, Revista OSAL, Año V. (13), 77-85. Buenos Aires: CLACSO. Recuperado en http://bibliotecavirtual.clacso.org.ar/clacso/osal/20110307011200/7ACTischler.pdf.

Zavaleta Mercado, R (1990). Notas sobre la cuestión nacional y Cuatro conceptos de democracia. En El Estado en América Latina. Obras completas. La Paz: Los amigos del libro.

Zegada, M. T. (et. al.) (2011). La democracia desde los márgenes: transformaciones en el campo político boliviano. Bolivia: CLACSO-Muela del Diablo.

\section{Para citar este artículo:}

Britos, A. (2016). Procesos de democratización. Derechos políticos y microesferas de lo público: tensiones y articulaciones políticas para un horizonte plurinacional. Collectivus, Revista de Ciencias Sociales, 3(2), 37-57. doi: http://dx.doi.org/10.15648/Coll.2.2016.3 